\title{
THE BIOCLIMATIC PARTICULARITIES \\ OF SUCEAVA MUNICIPALITY, ROMANIA
}

DOI: http://dx.doi.org/10.18509/GBP.2020.20

UDC: $551.588 .7: 551.506 .3(498)$

\author{
Dumitru Mihăilă ${ }^{1}$ \\ Petrut Ionel-Bistricean ${ }^{2}$ \\ Alin Prisacariu ${ }^{1}$ \\ Mihaela Țiculeanu - Ciurlică ${ }^{1}$ \\ Vasilică Horodnic ${ }^{1}$ \\ ${ }^{1}$ Department of Geography, Faculty of History and Geography, Stefan cel Mare University, \\ Suceava, Romania \\ ${ }^{2}$ Regional Meteorological Centre of Moldova, National Meteorological Administration, \\ Suceava, Romania
}

\begin{abstract}
Even though Suceava is a mid-sized city and the climatogenetics anthropogenic factors are not as ample as the ones from the large and very large cities, these have the capability to introduce important topoclimatic and bioclimatic modifications. Until the endowment of the stations SV1 and SV2, which belong to the National Network of Air Quality Monitoring, with performant automatic meteorological equipment and the displaying of the meteorological and air chemistry data in accessible format, not many things were known about the urban topoclimate and bioclimate of Suceava. The studies that targeted the internal urban topoclimate for Suceava are just a few, disparate, and do not cover intervals with more than a few days. Within this first bioclimatic study for Suceava we have approached the defining features of the periurban bioclimate (for a timeframe included between 1961 and 2018), and then we used these results as fundament for the comparative analysis (based on hourly average data and on monthly averages) of the THI, WCI, ITH indices calculated on the common interval 2009-2019 for Suceava weather station - SMS, SV1 and SV2. These indices have been validated by us in previous studies in which we showed their relevance or gaps. The results obtained highlight for Suceava (at least for those two urban nuclei of the city - the one from the south of Suceava valley and the one from the north of this valley) an internal bioclimate with different features compared to the one periurban.
\end{abstract}

Keywords: urban bioclimate, Suceava metropolitan area

\section{INTRODUCTION}

The bioclimatic researches place into another perspective the relationship between the human communities and the local climate. The research of the bioclimatic characteristics and specificity of the urban topoclimate is, through the light of the data obtained for the municipality of Suceava, an action as complex, as necessary and especially useful for authorities and common population. Why? Because, inside the city, there can be demonstrated (with the help of the observations made at the urban weather stations SV1 and SV2 in our case) the ocurrance of relevant bioclimatic differentiations compared to those noticed and calculated for the meteorological platforms of the regional weather stations (SMS). Within this context the townspeople are entitled to have the possibility to 
relate themselves to the bioclimatic reality in which they are currently performing their activity. The studies of urban topoclimatology and microclimatology are quite numerous and they often include significant parts or detailed references to the bioclimatic particularities (including those of bioclimatic risk) of some cities [1], [2], [3], [4], [5]. But the bioclimatic studies abound for a large number of tourist resorts with a balneoclimateric profile [6], [7], [8] and are insufficient for different cities in which the large part of the population is actually concentrated. For the municipality of Suceava this study marks the debut of the research in the bioclimatic differentiations urban - suburban territory in the city vicinity, although direct and numerous references regarding the Plateau of Suceava bioclimate, in which the municipality of Suceava enframes itself, were made in two previous bioclimatic studies [9a], [9b]. But those were only relying on data from Suceava regional weather station and were not including references to the bioclimate from inside the city.

The overall objective of the study consists in the evaluation, for the interval 1961-2018, on the basis of the data come from the SMS, of the main particularities of Suceava's bioclimate through some relevant bioclimatic indices: THI, WCI, the indices of related skin stress, the pulmonary stress index, ITU and which have been calculated for the monthly temporal resolution. Also, based on the hourly data from the urban wetaher stations SV1 and SV2 from the interval 2009-2019, we have subsequently determined, strictly for the urban atmosphere, the same monitored indices whom we have compared with those synchronous from the SMS. We have, in this way, captured the bioclimatic specificity of the urban atmosphere and the bioclimatic differentations that occur between the urban and suburban environments. As specific objectives we targeted i) the identification of the periods from an average year / day when in Suceava there are or there are not restrictions / problems generated by the particularities of the climate with direct or indirect reflex upon the population's comfort / discomfort or pathology, ii) the making of some models to monthly resolution for establishing the defining particularities of the bioclimate from within a year and to hourly resolution for those of the bioclimate at the scale of one day, differentiated on seasons and on day-night, and last but not least iii) the establishing of the relative values of the bioclimatic diferences between the suburban and urban environments of Suceava, in order to be able to quantify the influence exerted by the city in bioclimatic plan.

\section{MATERIALS AND METHODS}

\section{Study area}

The bioclimate is an important conditioning factor of the social and economic activities, but especially of the comfort / discomfort and health state of the people from the human settlements, regardless of their size. For the administration and inhabitants from municipality of Suceava, in which live, according to the data from the last official census from 2011, 116404 inhabitants, and which is visited annually by a few tens of thousands of tourists, knowing the detailed bioclimatic particularities is absolutely necessary. Suceava municipality has a temperate climate of transition, influenced by obvious differences between the two seasons of the year (warm-cold), with regard to the impact and the role played by the climatogenic factors, but also in respect of the elements values and the manifestation of some meteo-climatic phenomena [10], [11]. The interseasonal meteo-climatic differences and the meteorological excesses are a reality in Suceava [12] and they impose themselves in bioclimatic plan as well. But, inside the city, the local 
topoclimatic and microclimatic factors attenuate or accentuate the variability of a series of climatic elements and phenomena and, from here emerge the bioclimatic differentiations urban - periurban space, which are significantly important for certain periods from year / day and for different locations.

\section{Research Methodology}

The Methodology of approaching this study relies on two complementary directions of action: i) the first one of definition and analysis for a loger period $(1961-2018)$ of the bioclimatic particularities of Suceava based on the meteorological data processed and provided at monthly temporal resolution by the SMS and ii) the second one, of comparative analysis detailed on months, days and hours for a shorter interval (20092019, imposed by the fact that only from 2009 onwards there are meteorological data for the stations SV1 and SV2) of the bioclimatic similarities and differences between SMS and SV1 / SV2, highlighted statistically and graphically.

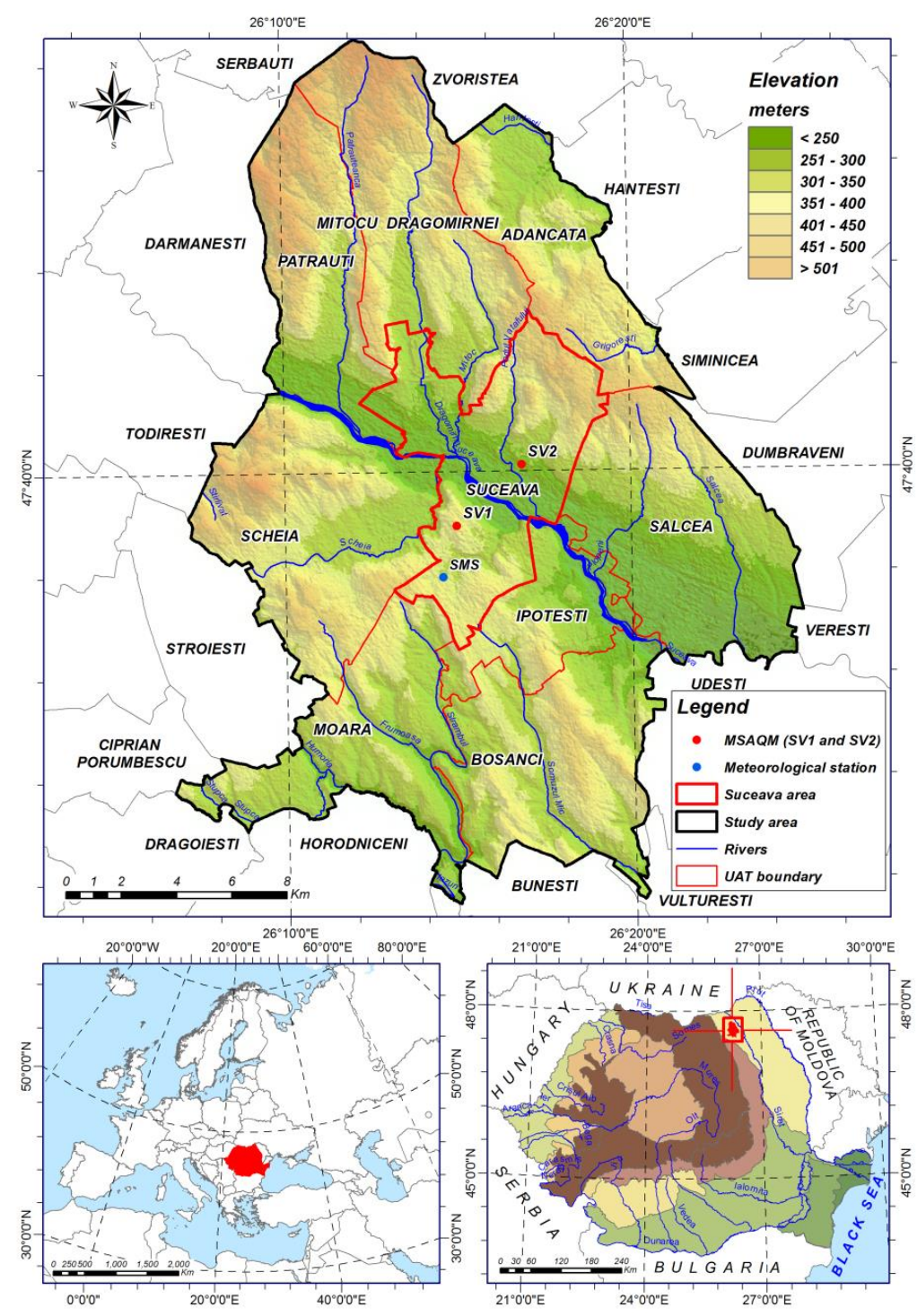

Figure 1 The localization of Suceava metropolitan area within the local geographical and mathematical context, of Suceava meteorological station - SMS and of the meteorological and air quality monitoring stations - MSAQM - SV1 and SV2 (up), of Suceava metropolitan area within the space of Romania (down right) and of Romania within Europe (down left) 


\section{Data and methods}

We've had the monthly meteorological data processed in the form of climatic and bioclimatic indices for Suceava meteorological station (positioned on the coordinates $47^{\circ} 37^{\prime} 57.087^{\prime \prime} \mathrm{N}, 26^{\circ} 14^{\prime} 32.243 " \mathrm{E}$ at $359 \mathrm{~m}$ altitude) for the interval 1961-2018. These were used for the overall bioclimatic characterization of Suceava. The second set of data is represented by the hourly ones (processed then to the point of hourly, daily and monthly indices) for the stations SV1 (positioned on the coordinates $47^{\circ} 38^{\prime} 57.2^{\prime \prime} \mathrm{N}, 26^{\circ} 14^{\prime} 56.7^{\prime \prime} \mathrm{E}$ at $359 \mathrm{~m}$ altitude) and SV2 (positioned on the coordinates $47^{\circ} 40^{\prime} 08.8^{\prime \prime} \mathrm{N}, 26^{\circ} 16^{\prime} 51.0^{\prime \prime} \mathrm{E}$ at the altitude of $289 \mathrm{~m}$ ) and which were analyzed comparatively to the ones from the SMS. The bioclimatic indices were rigurously selected on the basis of the results that we obtained within a previous bioclimatic study, referring to the whole territory of Moldavia [13]. All the bioclimatic indices taken into analysis present a series of small deficiencies, but they have been selected in such a manner so that to cover, for certain significant periods of the year, and from different angles, the relevant bioclimatic particularities of the analyzed location.

\section{RESULTS AND DISCUSSIONS}

The results predicted have anticipated the realization of some suggestive graphical models which illustrate the specific of Suceava's bioclimate (periurban space / urban space) for different time intervals (multiannual, annual, diurnal) and identify the months and hours with bioclimatic comfort or discomfort in different degrees within these models.

A primary index used was $\boldsymbol{T H I}$ propsed by Kyle in 1994 [14]. Its calculation formula is [1']:

$$
T_{H I}^{\circ} \mathrm{C}=\text { Tusc }-(0.55-0.0055 \times U R)(T u s c-14.5)\left[1^{\prime}\right]
$$

in which Tusc represents the air temperature in ${ }^{\circ} \mathrm{C}$ measured at dry thermometer, and UR - relative humidity $(\%)$.

The index has representativity for every month of the year or hour of the day and illustrates with enough accuracy the succession of the bioclimatic conditions and of the intervals of comfort, discomfort through cooling or heating, whom the human body is subject to. The interpreting of the results obtained through this index has been done by reporting its values to a scale already known and validated [13] - Tab. 1.

Table 1. The THI threshold values $\left({ }^{\circ} \mathrm{C}\right)$ a), bioclimatic conditions b) and the relationship with the thermal sensations felt by the human body c)

\begin{tabular}{|c|c|c|}
\hline a) THI index $\left({ }^{\circ} \mathbf{C}\right)$ & b) Bioclimatic conditions & c) Type of bioclimatic comfort/discomfort \\
\hline$-20<\mathrm{THI}=-10$ & Excessive cold & \multirow{3}{*}{ Bioclimatic discomfort due to overcooling } \\
\hline$-10<\mathrm{THI}=-1.8$ & Very cold & \\
\hline$-1.8<\mathrm{THI}=+13$ & Cold & \\
\hline$+13<\mathrm{THI}=+15$ & Cool & \multirow{2}{*}{ Bioclimatic discomfort due to overheating } \\
\hline$+15<\mathrm{THI}=+20$ & Comfortable & Warm \\
\hline$+20<\mathrm{THI}=+26.5$ & Very hot & \\
\hline$+26.5<\mathrm{THI}=+30$ & Torrid & \\
\hline $\mathrm{THI}>30$ & &
\end{tabular}

Within an average year, at Suceava, the course and the average values of this index indicate the fact that during the summer months the human body feels comfortable in the 
thermo-hygrian ambience from the urban periphery in the JJA months and, to a lesser extent, in the months $\mathrm{M}$ and $\mathrm{S}$, when a slight thermic discomfort through cooling is dominant - Fig. 2.

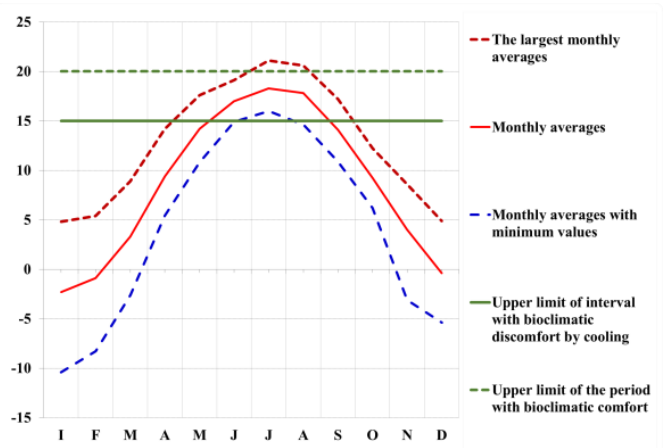

Figure 2. The annual regime of the THI $\left({ }^{\circ} \mathrm{C}\right)$ parameters at Suceava meteorological station (1961-2018)

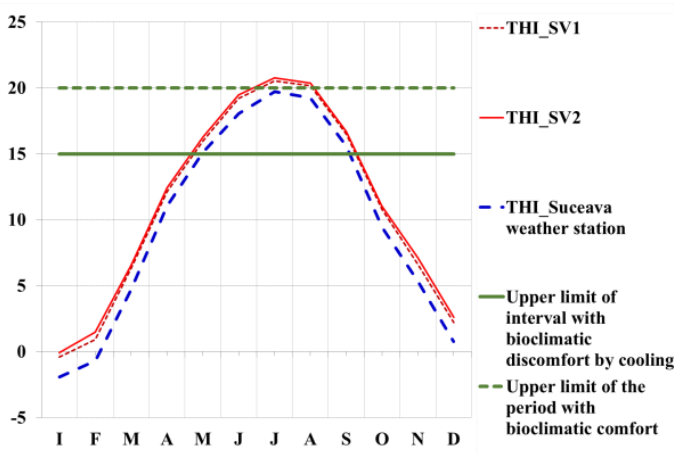

Figure 3. The annual regime of THI $\left({ }^{\circ} \mathrm{C}\right)$ at Suceava meteorological station and at the stations SV1 and SV2 (2009-2019)

The displaying on months of the effective average values of THI - Fig. 4, illustrates the fact that during the cold season months (ONDIFM) dominant is the discomfort through cooling, which reaches the maximum intensity in the winter months (being possible to take place, according to the values and to the THI appreciation grid, excessively cold months too), and in those of the hot season (AMJJAS) dominant are the comfortable months (JJA), comfortable and with a slight discomfort through cooling (MS) and chilly (A). After 1990, on the background of the regional warming, in the months JA have also appeared, with an increasing frequence (after 2007), months with discomfort through heating, too - Fig. 4.

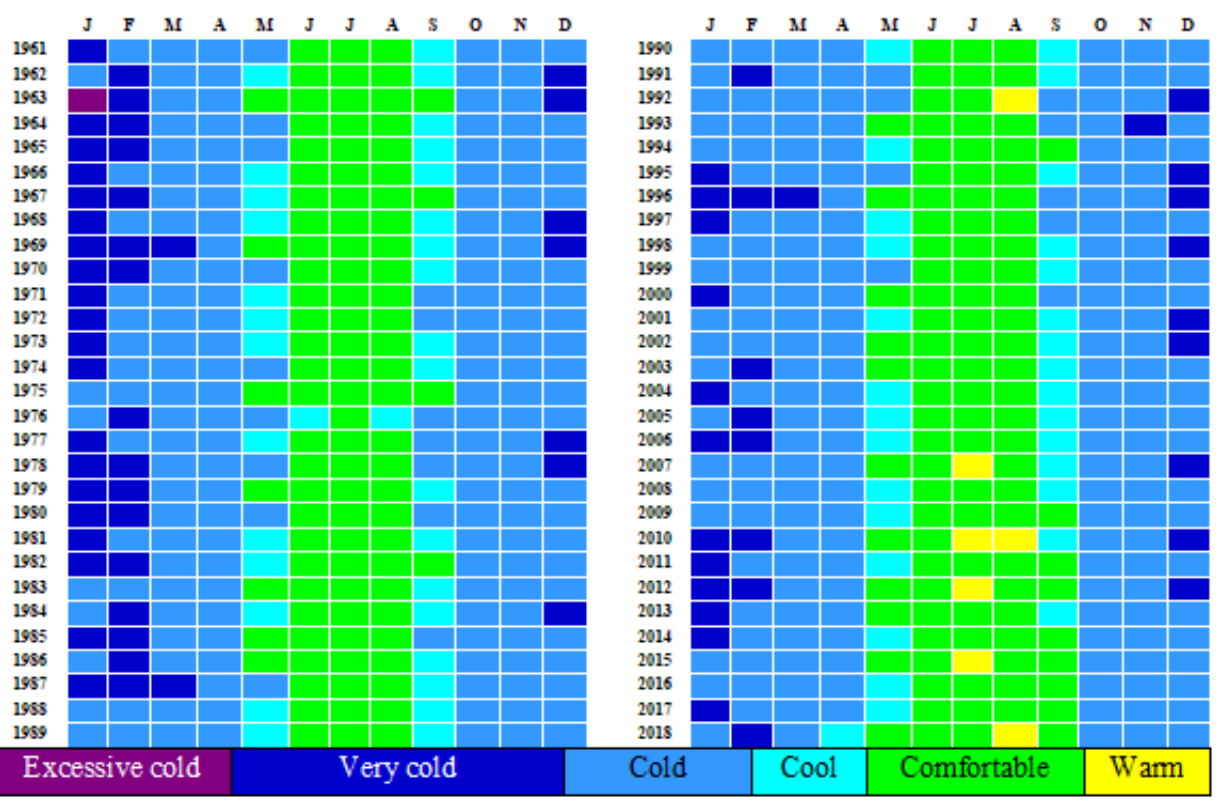

Figure 4. The multiannual regime of the bioclimate character (established for Suceava weather station on the basis of THI values $-{ }^{\circ} \mathrm{C}$ ), detailed on months, on the basis of data from the SMS (1961-2018)

By comparing the annual regime of the THI index at SMS with the one from the stations SV1 and SV2 (Fig. 3) we notice that in the interval 2009-2019 the average annual period 
of thermic comfort extended itself to the interval MJJA - on the background of the regional and local warming of the atmosphere and also that, at SV! And SV2 the THI values indicate, every month, a slight superiority related to those from the SMS, an indication that in the city, the degree of bioclimatic comfort is superior to that from the urban periphery.

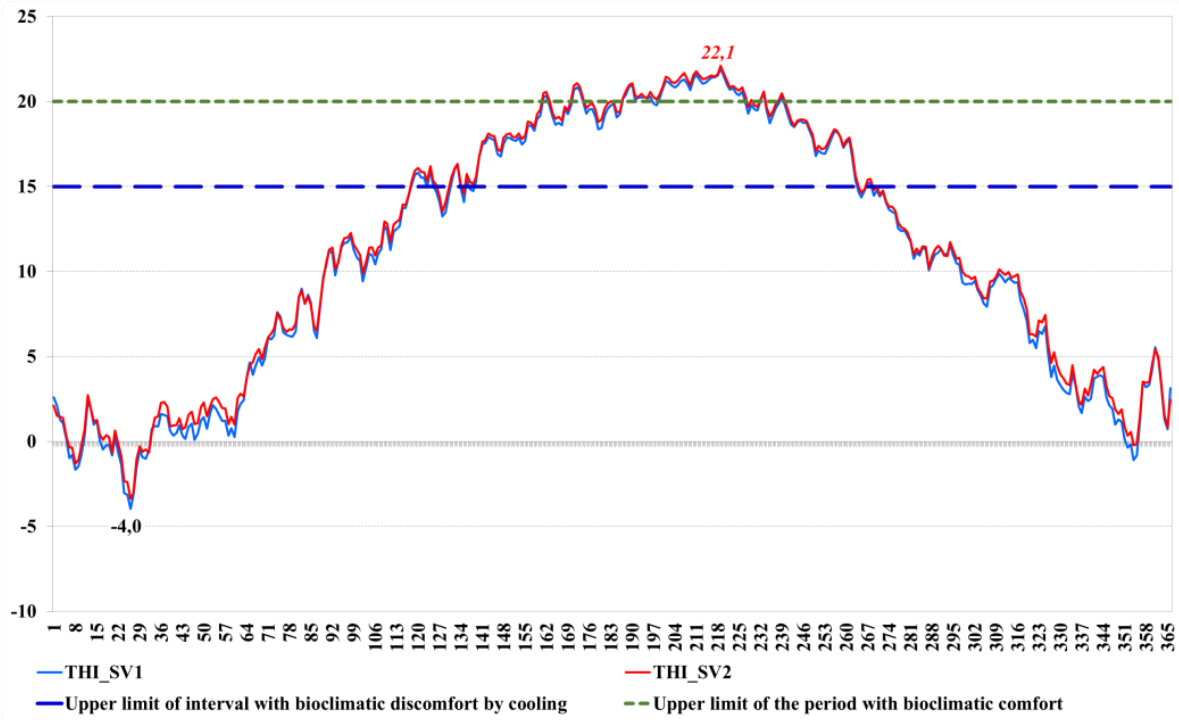

Figure 5 The annual regime of the daily average values of the THI $\left({ }^{\circ} \mathrm{C}\right)$ for the stations SV1 and SV2 (2009-2018)

The interdiurnal course of the THI within an average year - Fig. 5 discloses a more comprehensive reality: the one that during the days from the core and from the last third of the summer the diurnal entities with thermic discomfort through heating shape themselves as a statistical and graphical reality clearily identified. The interdiurnal variability of the index catches closer to the reality the THI regime.

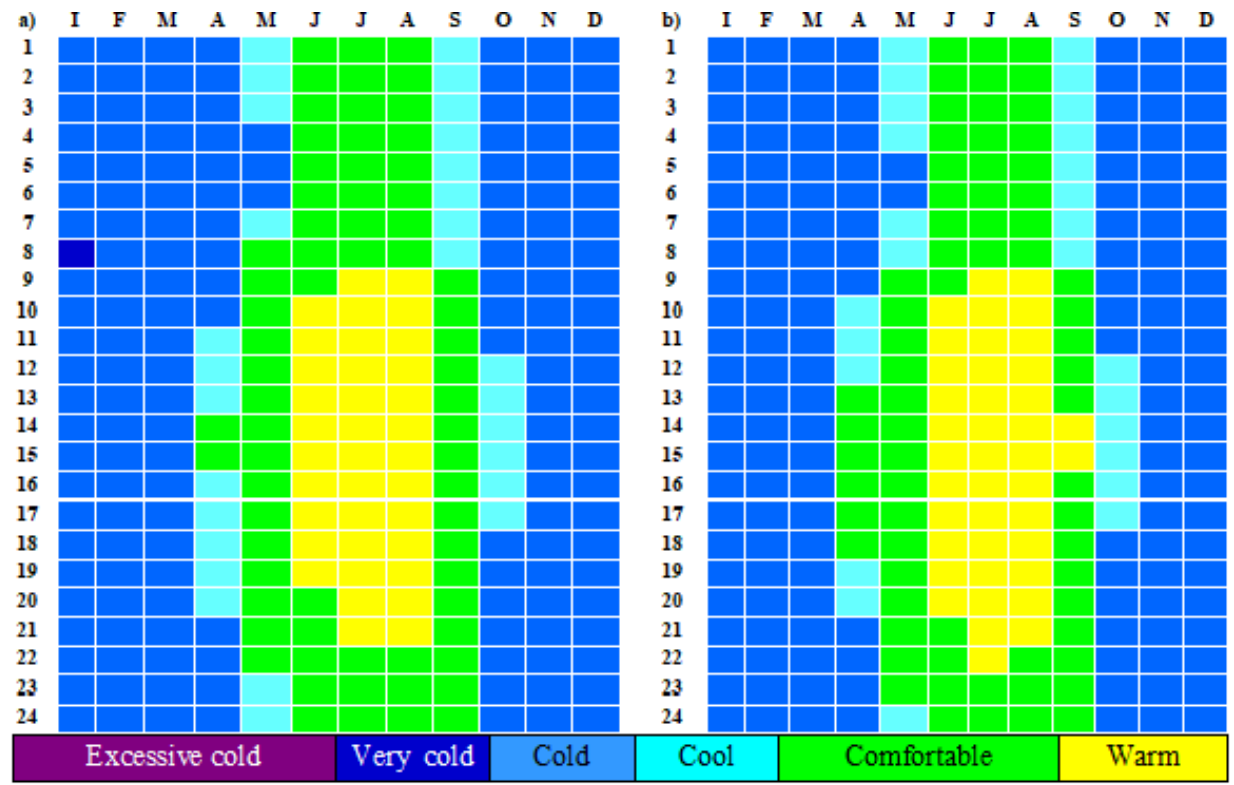

Figure 6. The characteristics of the bioclimate over the months from a year and the hours from a day on the basis of THI at the stations SV1 a) and SV2 b) 
The analysis at an even more detailed level (the isophlet analysis) of the average values of the THI highlights for SV1 and SV2 more clearly and more realistically the temporal and spatial distribution of the intervals with comfort or discomfort through heating and cooling within a year and a day. During the summer months, inside the city, clearly appears the diurnal interval included between 9-10 hours and respectively 19-22, in which the discomfort through heating acts - Fig. 6 .

The second index taken into analysis is the chilling power of the wind - WCI. Even though it has a representativity higher for winter and the cold season, it offers, by the way of comparison, suggestive results for the warm season of the year, too. The wind chilling power index has been claculated through the formula [2'] configured by Siple and Passel, 1945 [15].

$\mathrm{WCI}=(10 \sqrt{V}+10,45-v) \cdot(33-t)\left[2^{\prime}\right]$

where:

WCI - represents the chilling power of the wind expressed in $\mathrm{kcal} / \mathrm{m}^{2} / \mathrm{h}$

$\mathrm{t}$ - the temperature of the dry thermometer $\left({ }^{\circ} \mathrm{C}\right)$;

$\mathrm{v}-$ the wind speed $(\mathrm{m} / \mathrm{s})$.

The correspondence between its values, the skin stress index, the time character and the type of stress induced is illustrated in Tab. 2.

Table 2. The chilling power of the wind $\left(\mathrm{kcal} / \mathrm{m}^{2} / \mathrm{h}\right)$ and the significance of the skin biostress index

\begin{tabular}{|c|c|c|c|}
\hline $\begin{array}{c}\text { The chilling power of the } \\
\text { wind }\left(\mathrm{kcal} / \mathrm{m}^{2} / \mathrm{h}\right)\end{array}$ & $\begin{array}{c}\text { Indices of } \\
\text { skin stress }\end{array}$ & $\begin{array}{c}\text { Character } \\
(\text { significance })\end{array}$ & Type of stress \\
\hline $0-149$ & -2 & hypotonic & $\begin{array}{c}\text { stress by triggering thermalisation } \\
\text { during the summer }\end{array}$ \\
\hline $150-299$ & -1 & hypotonic & $\begin{array}{c}\text { stress by triggering thermalisation } \\
\text { during the summer }\end{array}$ \\
\hline $300-599$ & 0 & relaxing & not requiring thermoregulation \\
\hline $600-899$ & +1 & hypertonic & $\begin{array}{c}\text { stress by triggering thermogenesis } \\
\text { in winter }\end{array}$ \\
\hline $900-1199$ & +2 & hypertonic & $\begin{array}{c}\text { stress by triggering thermogenesis } \\
\text { in winter }\end{array}$ \\
\hline $1200-1499$ & +3 & hypertonic & $\begin{array}{c}\text { stress by triggering thermogenesis } \\
\text { in winter }\end{array}$ \\
\hline$>1500$ & +4 & hypertonic & stress by triggering thermogenesis \\
in winter
\end{tabular}

Based on the monthly average data from the SMS (1961-2018) this index indicates the manifestation of the bioclimatic comfort during the months MJJAS - Fig. 7. If we analyze in a more detailed manner the valoric and qualitative spreading of this index for each month of the interval 1961-2018 - Fig. 9, we can notice the fact that the anual interval of comfort expands itself to its ends towards the months $\mathrm{A}$ and $\mathrm{O}$ and it is interrupted, more and more frequently, after 1990, exactly in its core, by stressful months - but not in a very high degree (the value of the skin stress index is -1 ), in terms of caloric surplus. The interval ONDIFM is with caloric deficit, and within this the months DIF highlight themselves when the deficit is important (the skin stress indices reach on monthly averages the value $+2-$ Fig. 9 and Tab. 2) 


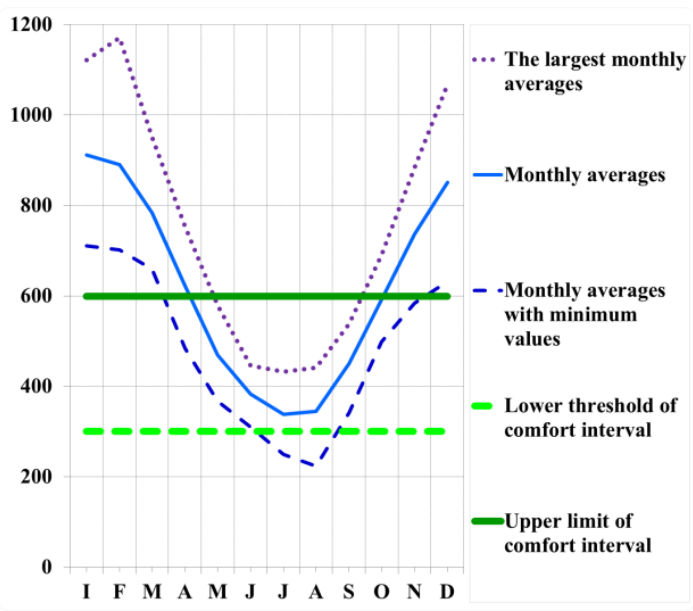

Figure 7. The annual regime of the WCI $\left(\mathrm{kcal} / \mathrm{m}^{2} / \mathrm{h}\right)$ parameters at SMS $(1961-2018)$

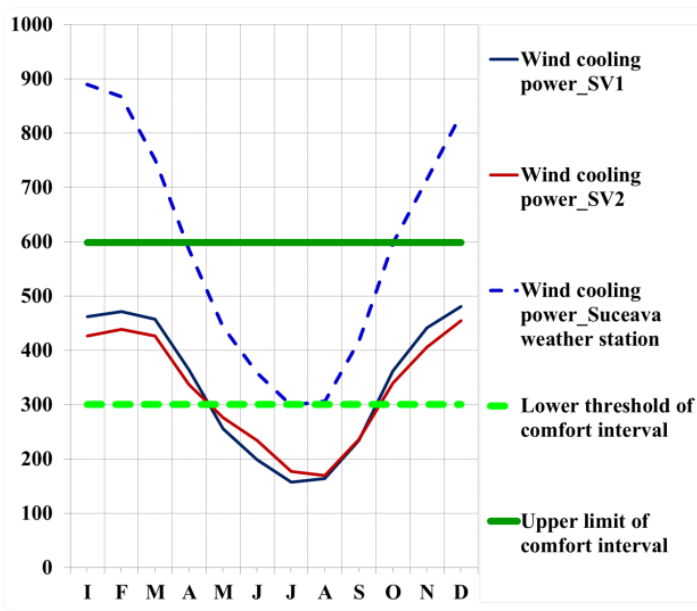

Figure 8. The annual regime of the WCI $\left(\mathrm{kcal} / \mathrm{m}^{2} / \mathrm{h}\right)$ at SMS and at the stations SV1 and SV2 (2009-2019)

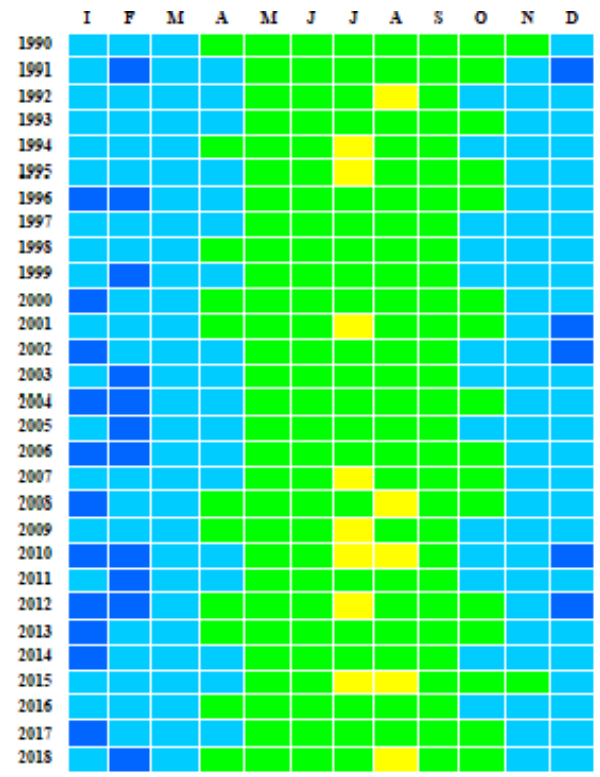

Figure 9. The multiannual regime of the bioclimate character (established on the basis of the WCI values - $\mathrm{kcal} / \mathrm{m} 2 / \mathrm{h}$ ), detailed on months, on the basis of the data from the SMS (1961-2018)

By comparing the monthly average values of the WCI from the SMS with the ones from SV1 and SV2 for the period 2009-2019 - Fig. 8 we can notice for the SMS the extension of the annual period with bioclimatic comfort (to the months AMJJASO) in comparison with that of the longer period (1961-2018), in which it integrates itself and in which the comfort was characteristic only to the MJJAS months. This is another proof of the regional warming of the atmosphere, aspect proved quite a while ago [16]. The most interesting is the fact that, the values of the WCI are being diminished with almost $50 \%$ inside the city in raport to its periphery. At least during the cold season, the urban atmosphere is much more friendly, from bioclimatic point of view, that the one from the city vicinities. The discomfort through cooling dissapears from the city, but instead 
appears very clearly an annual interval (from $\mathrm{M}$ till $\mathrm{S}$ ) in which the discomfort through heating is well illustrated statistically, graphically and in the daily bioclimatic reality.

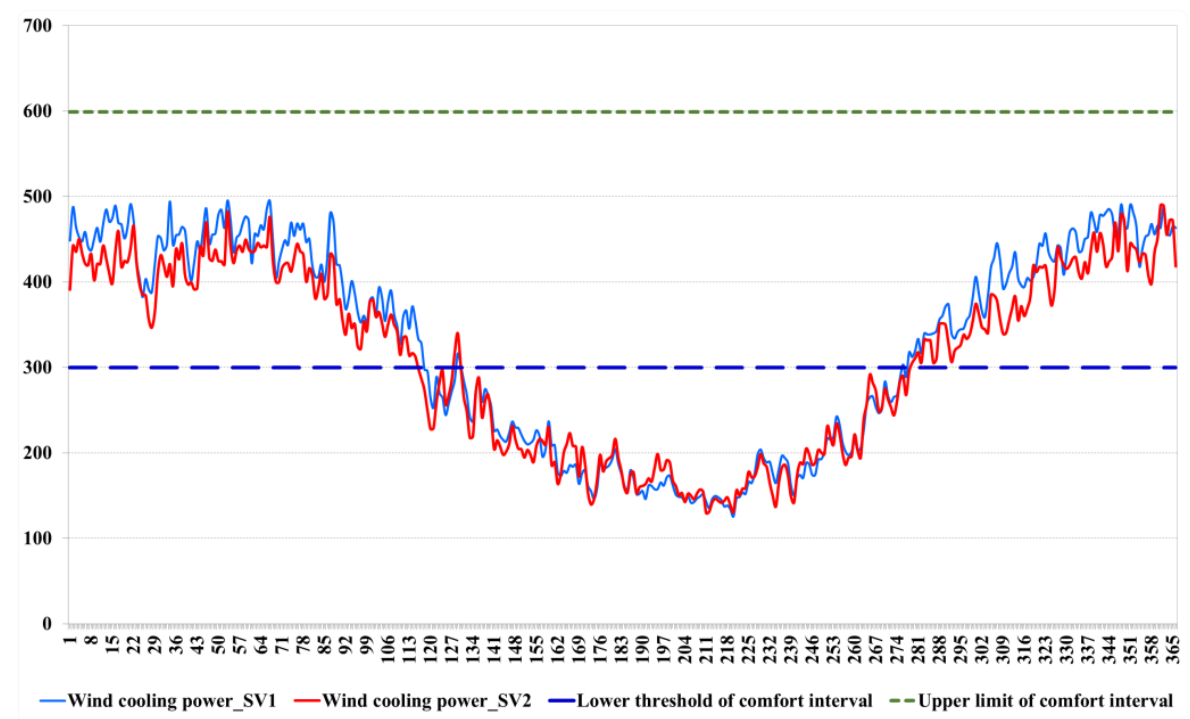

Figure 10. The annual regime of the daily average values of the WCI for the stations SV1 and SV2 (2009-2018)

Those stated on the basis of the data from Fig. 8 are strengthened, confirmed and detailed by the data from Fig. 10 on which we can notice a valoric superiority of the WCI at SV1 during the cold season, faded, annulled and even inverted on a considerable length of the warm semester by the WCI values from SV2.
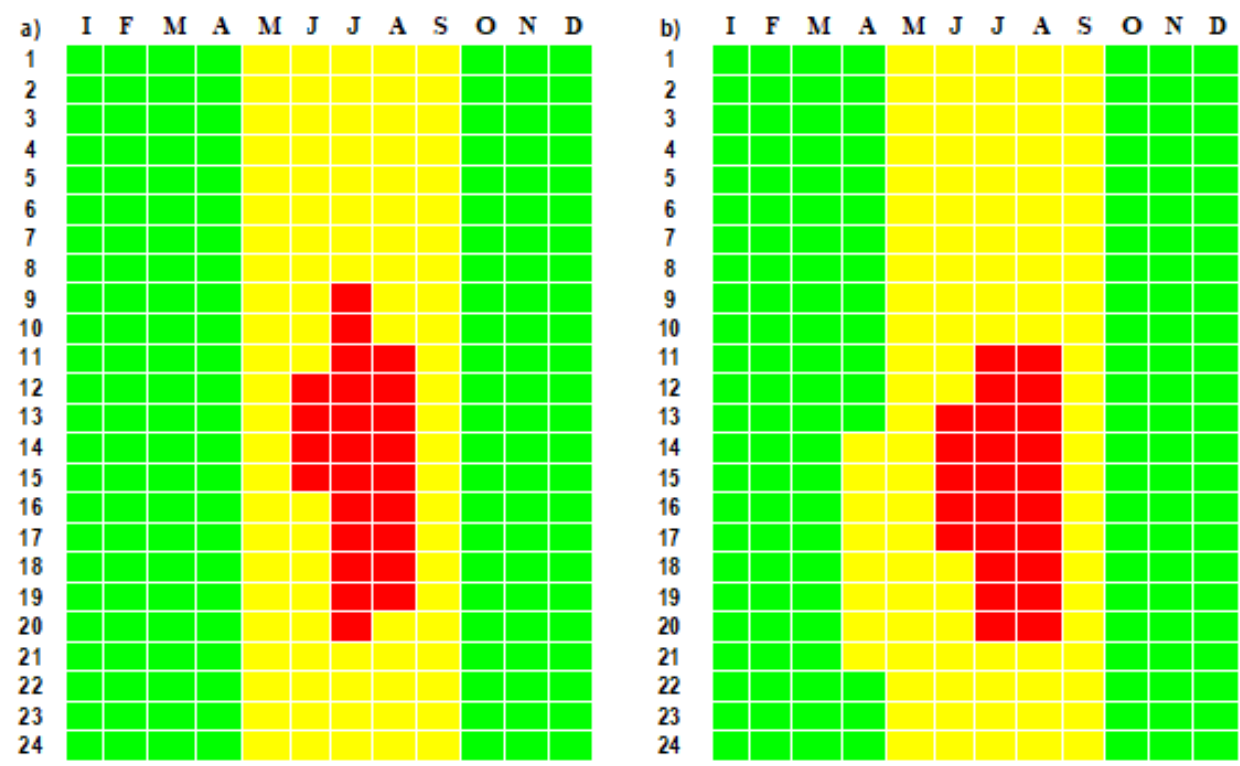

Figure 11. The bioclimate characteristics over the months from a year and hours from a day based on the WCI index at the stations SV1 a) and SV2 b)

Furthermore, the isopleth representations of the WCI from SV1 and SV2 - Fig 11, outlines for the months JJA and for the hourly interval 9-11 and 19-20, a stressful time because of the heat, on the background of the WCI value drop below the threshold of 149 $\mathrm{kcal} / \mathrm{m} 2 / \mathrm{h}$ and of the skin stress index to values of -2 . The higher degree of 
particularization of the isopleth representations allows us to identify and to quantify with more precision the bioclimate impact upon the humans for all intervals of time (from hour to month) from a year.

Without stepping into many details, we have tried to draw for the SMS the major coordinates of the pulmonary stress, as well. We've made use of its estimation scale based on the values of the water vapors real tension distributed by Becancenot in 1974 on different thresholds, quantified by indices and different marks [17].

Table 3 Index of pulmonary stress depending on the water vapor pressure

\begin{tabular}{|l|c|l|}
\hline Water vapor tension $(\mathrm{e})$ & Index & Type of stress \\
\hline $0-4.0$ & $(+2)$ & dehydrating in winter \\
\hline $4.1-7.4$ & $(+1)$ & dehydrating in winter \\
\hline $7.5-11,6$ & 0 & equilibrate \\
\hline $11.7-15.9$ & $(-1)$ & hydrating during summer \\
\hline $16.0-21.1$ & $(-2)$ & hydrating during summer \\
\hline $21.2-26.5$ & $(-3)$ & hydrating during summer \\
\hline $26.6-31.2$ & $(-4)$ & hydrating during summer \\
\hline
\end{tabular}

With the help of Tab. 3 and based on Fig. 12 we can place the most of the AM, SO months into the category unstressful from a hygric perspective, months JJA into those with pulmonary stress due to the overhydration, and the months NDIFM into the category of the months stressful through dehydration.
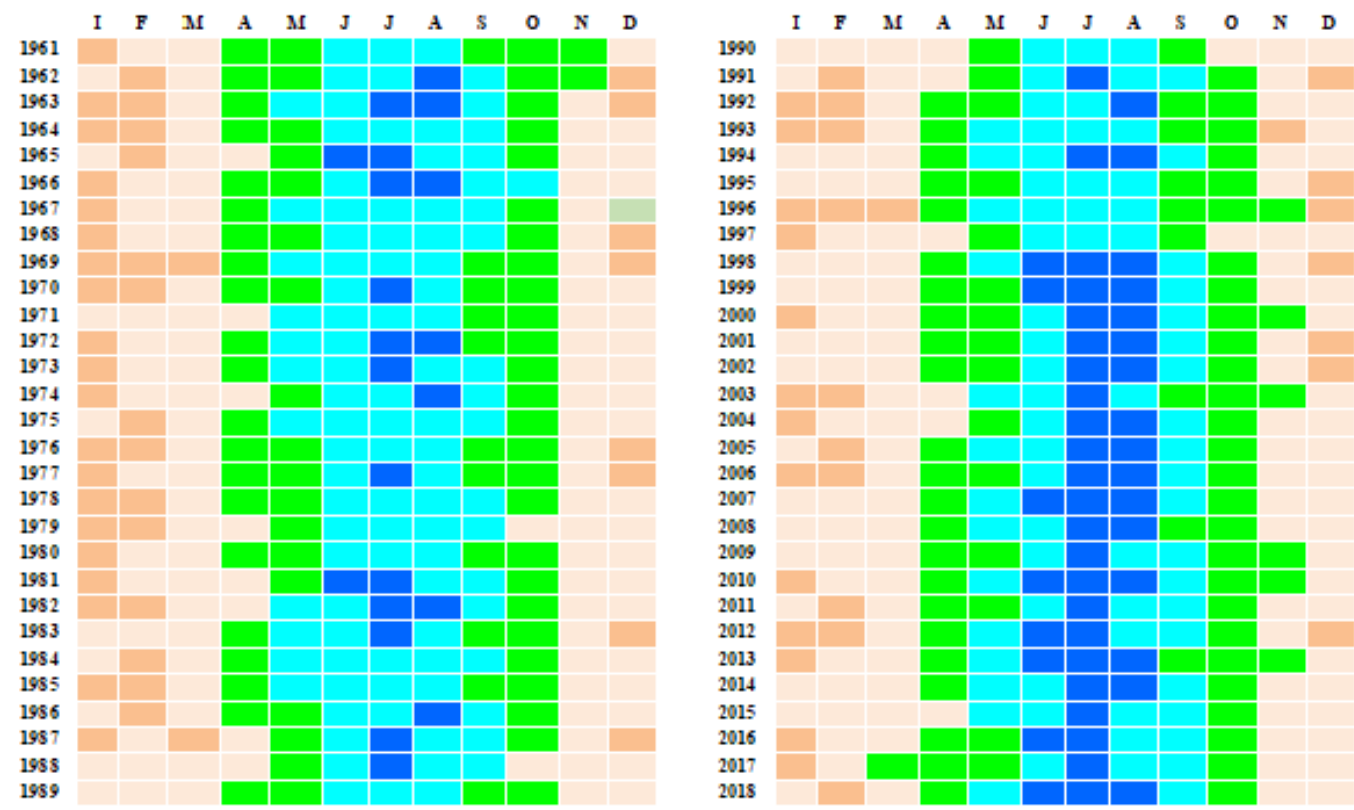

Figure 12. The multiannual regime of the pulmonary stress index depending on the water vapor pressure, detailed on months, determined on the basis of the data from the SMS (1961-2018)

Within the city, on the background of the humidity values drop in general, but also on the increase of the urban atmosphere capacity to absorb water vapors, due to the higher temperature, important mutations of this index of aditional stress take place, increasing the general degree of the urban bioclimatic stress stimulation, especially during the summer months (by the in-time accentuation of the hydrating stress) and of its decreasing during the winter time (by the dehydrating stress diminshing). The comfortable intervals (hours, days, months) have a disrupted evolution in relation to the dilution of the 
bioclimatic specific of the transitional seasons (especially during the first half of spring and the second part of autumn).

Another index with a particular significance in the register of the extrem bioclimatic stress / risk is the $\boldsymbol{I T H}$. This index has been analyzed and utilized in many studies [9a], [17], [18], [19]. For Moldavia and the Plateau of Suceava at the same time, this index's representativity is reduced mainly to the timeframe of the warm season, especially of the summer months, but not in their overall. The representativity of the index limits itself especially to the hot days and to the days with average and overaverage humidity. The moisture - temperature index expressed in units recommended by the WMO is obtained by using the formula [3']:

$\mathrm{ITH}=(\mathrm{T} \times 1.8+32)-(0.55-0.0055 \times \mathrm{U})[(\mathrm{T} \times 1.8+32)-58]\left[3^{\prime}\right]$

in which $\mathrm{T}=$ temperature $\left({ }^{\circ} \mathrm{C}\right)$ meteorological shelter height $(2 \mathrm{~m}) ; \mathrm{U}=$ relative humidity $(\%)$ at the same level.

Thermal comfort or discomfort is assessed in accordance with the following scale values: ITH $\leq 65$ units indicates the comfort, $66 \leq \mathrm{ITH} \geq 79$ indicates the alert and ITH $\geq 80$ units shows discomfort.

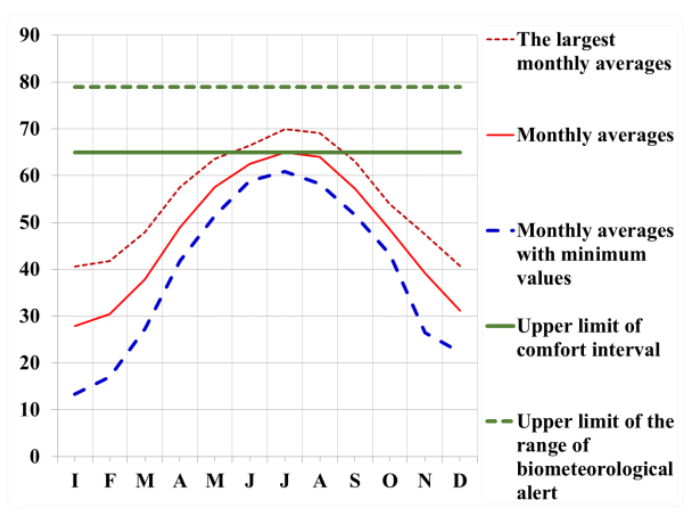

Figure 13. The annual regime of the ITH index parameters at the SMS (1961-2018)

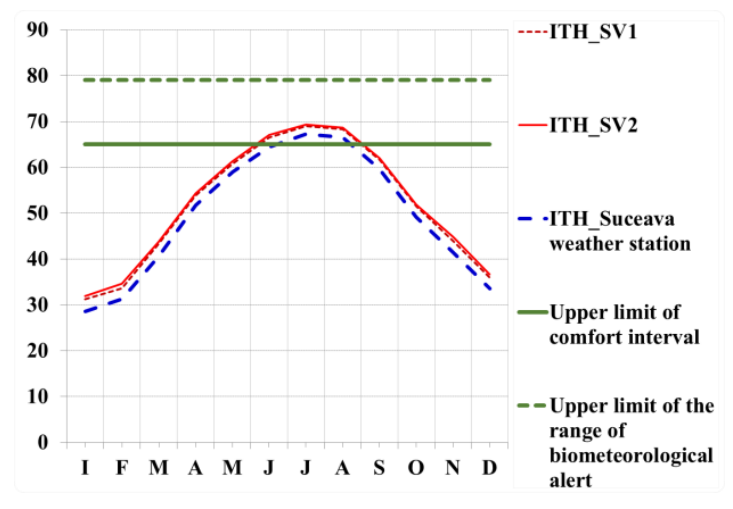

Figure 14. The annual regime of the ITH at SMS and at the stations SV1 and SV2 (2009-2019)

We have kept for analysis the interval September - May too, especially to emphasize the limits of this index which, on monthly averages, at SMS, reaches during JA only the superior threshold of the interval of bioclimatic comfort, and on the ITH averages with the highest values it places itself on the months JJA within the biometeorological alert interval - Fig. 13. Spread out on months (1961-2018) the ITH statistics from the SMS shows with enough accuracy the situation illustrated, only that, as in the case of the previos indices (THI, WCI), after 1990, on the background of the regional warming of the atmosphere, the frequency of the summer months with ITH values in the field of the interval of biometeorological alert has increased - Fig. 15. By analysing comparatively the annual regimes of the ITH built on the basis of the data of temperature and humidity from the SMS, SV1 and SV2 for the interval 2009 - 2019, we can notice the slight valoric increase of the index for SMS ( at least at the level of the summer months) and also the valoric superiority, month by month, of the ITH at the stations SV1 and SV2, compared to those from the SMS (Fig. 14). 


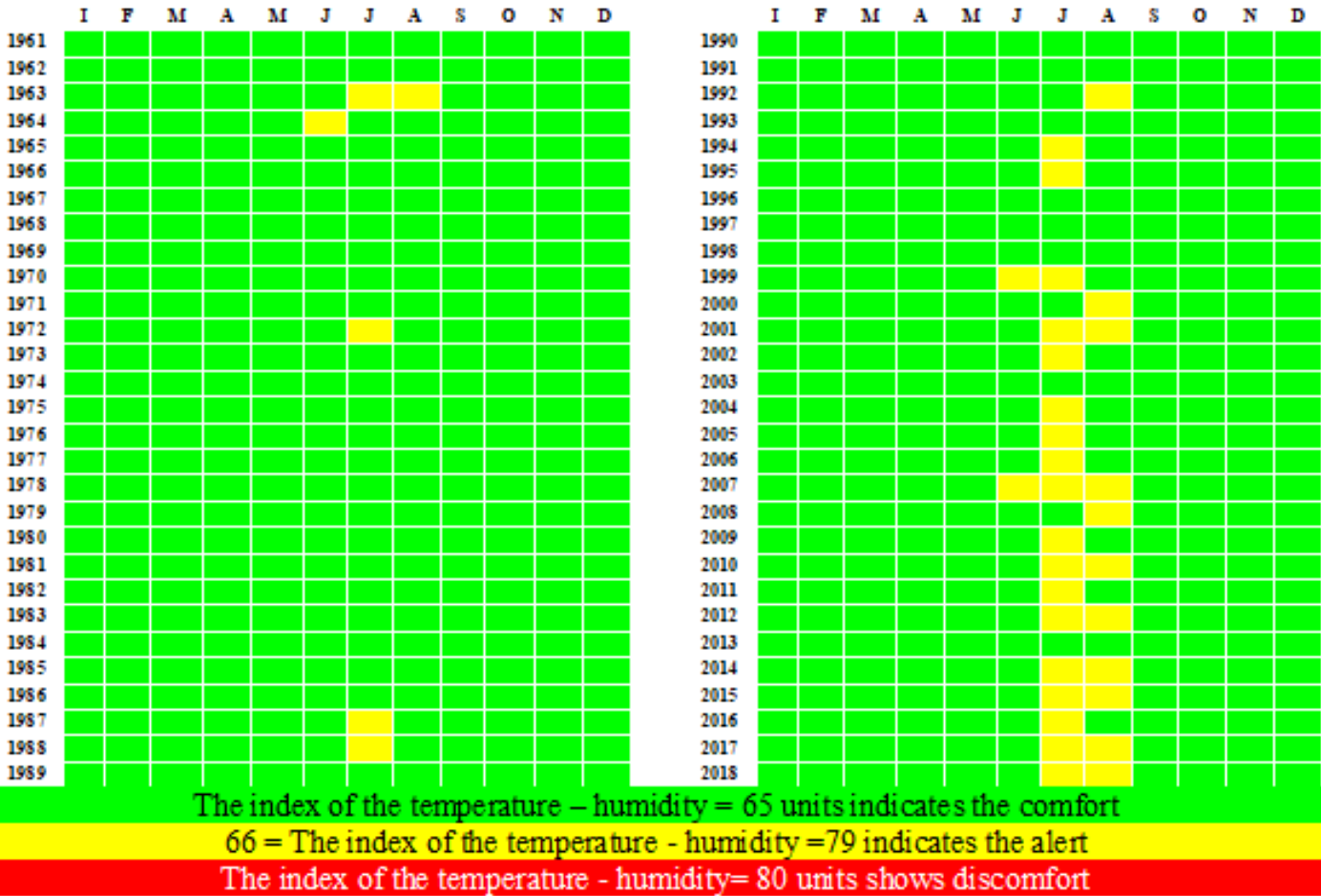

Figure 15. The multiannual regime of the bioclimate character (established on the basis of the ITH values), detailed on months, based on the data from the SM (1961-2018)

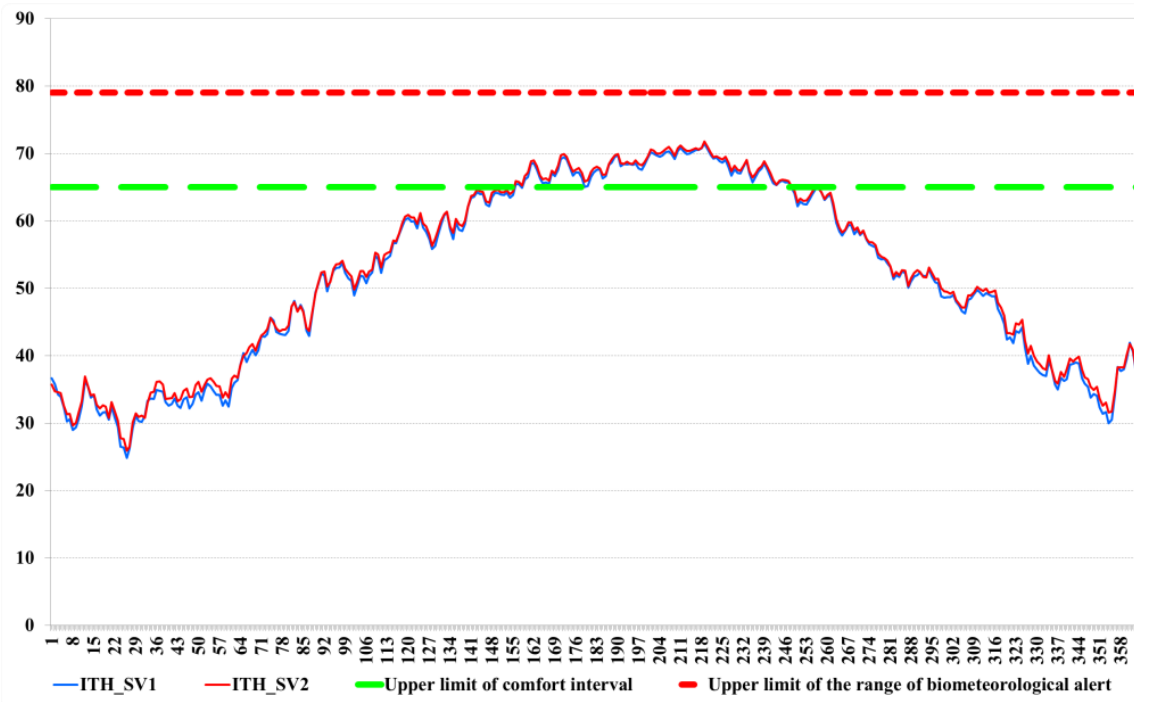

Figure 16. Annual regime of daily average ITH values for stations SV1 and SV2 (2009-2018)

On days, the valoric course of the ITH at SV1 and SV2 indicates for the interval 20092019 that its values soar approximately two months of summer within the interval of biometeorological alert, but it is still far from the threshold of of 80 units - Fig. 16. It is a sufficiently important signal which must alert us because, beginning with the year 1990, the particularities of the urban bioclimate have deteriorated themselves a lot during the summer time and especially during the heating waves, more and more frequent in this season and to the latitudes of Suceava. The isophlets ITH for SV1 show that at this station the value of the index in discussion maintain themselves within the interval of 
biometeorological alert from the month J till S (on variable hourly intervals which, during the month of July, get to expand themselves between the hours 8 and 24), and at SV2 from the month M till S (on variable hourly intervals which, in the month of July, get to expand themselves between the hours 8 and 24) - Fig. 17 .

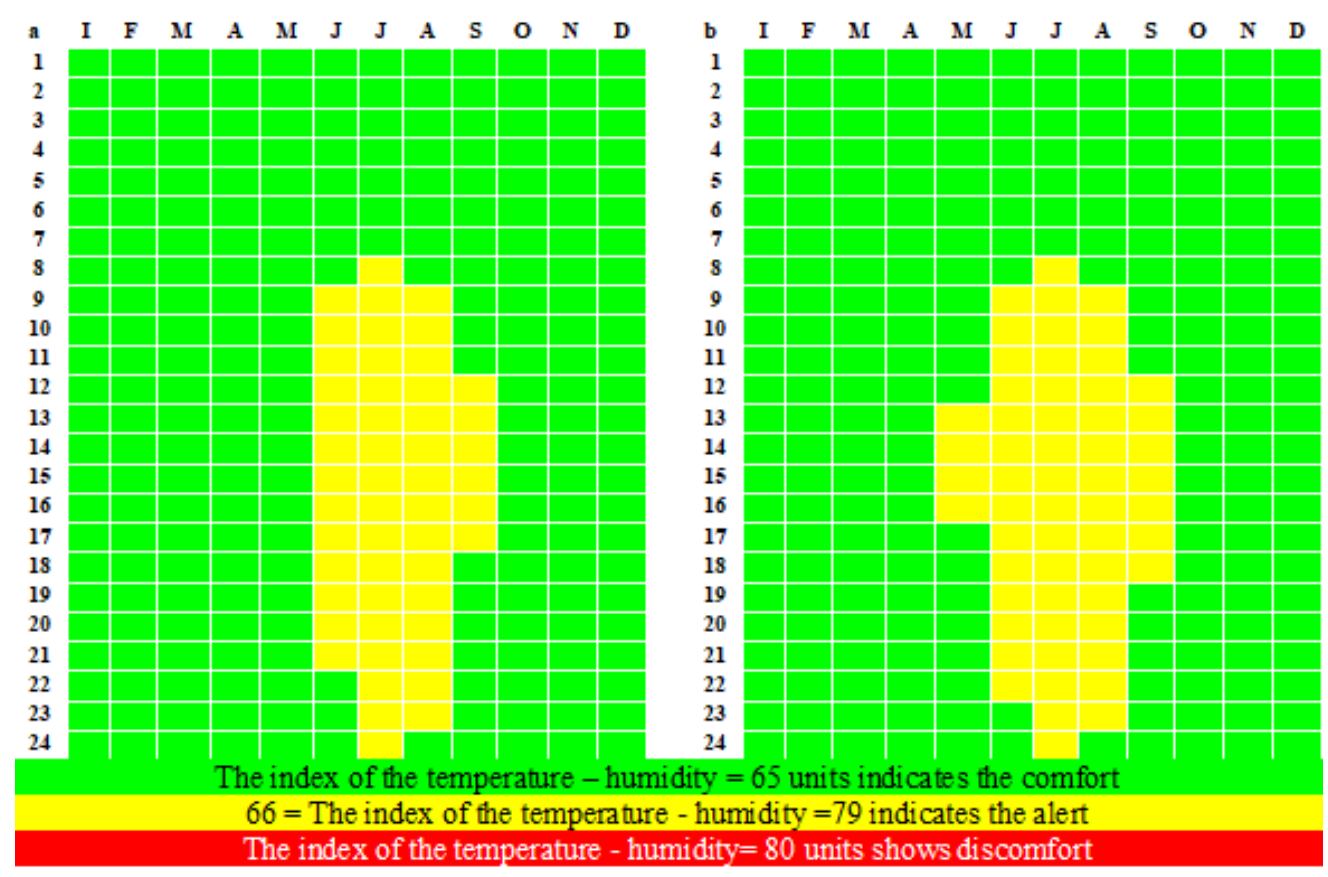

Figure 17 The bioclimate characteristics over the months from a year and hours from a day on the basis of ITH at the stations SV1 a) and SV2 b)

So, the timeframe of the interval with thermic discomfort through heating is very well represented at those two stations.

\section{CONCLUSIONS}

Through this study we have captured the differentiations between the periurban and urban bioclimate which, in essence, can be summarised through: the superior month by month values of the TCI and ITH from SV1 and SV2 comparatively to SMS. We have noticed that the WCI values are almost double at SMS comparatively to SV1 and SV2. The urban atmosphere presents an attenuation of the discomfort through cooling in winter (the cold season) and an accentuation of the discomfort through warming in the summer (the hot season). All these differentiations have increasingly amplified in time at the urban stations rather than at the SMS, leading to: the expansion and the amplifying of the bioclimatic risk intensity due to the warming during the summer time to the the end of spring and beginning of autumn, to the compression of the intervals with bioclimatic comfort from the spring / autumn time and to the attenuation of the bioclimatic discomfort due to the cold during the winter. The urban bioclimate has become softer in the winter / cold season and more demanding during the summer / hot season time. By taking into account the urban dynamics and the current climatic trend, we can say that these periurban-urban differentiations will increase. The comprehending by the administration, population and by the medical sector of these specificities and tendencies is necessary for the good management of the social and economical life of Suceava. 


\section{REFERENCES}

[1] Landsberg H. E. The Urban Climate, International Geophysics Series, Vol. 28, University of Mariland, 1981.

[2] Fărcaș I. Clima urbană, Editura Casa Cărţii de Ştiinţă, Cluj-Napoca, 1999.

[3] Fărcaş I. Zona industrială Turda-Câmpia Turzii, studiu bioclimatic, teză de doctorat, Facultatea de Geografie, UBB Cluj-Napoca, 1977.

[4] Gugiuman I., Cotrău M. Elemente de climatologie urbană cu exemple din Romania, Editura Academiei, Bucureşti, 1975.

[5] Laaidi K., Zeghnoun A., Dousset B., Bretin Ph., Vandentorren St., Giraudet Emm., Beaudeau P. The Impact of Heat Islands on Mortality in Paris during the August 2003 Heat Wave, Environ Health Perspect 120:254-259, 2012.

[6] Teodoreanu E., Dacos-Swoboda M., Voiculescu-Ardeleanu C., Enache L. Bioclima staţiunilor balneoclimatice din România, Edit. Sport-Turism, Bucureşti, 1984.

[7] Teodoreanu E., Gaceu O. Turism balneoclimatic în România, Editura Universității din Oradea, 223 p., 2013.

[9] Enache L. Biometeorologie și bioclimatologie. Climatul și bioclimatul stațiunilor balneare și România, Editura Sitech, Craiova, 582 p, 2016.

[9a] Teodoreanu E., Mihăilă D. Is the bioclimate of Suceava Plateau confortable or unconfortable? Analysis based on TEE and THI, PESD, Vol. 6 no. 1/2012, 2012.

[9b] Teodoreanu E., Mihăilă D. Is the bioclimate of Suceava Plateau confortable or unconfortable? Analysis based on wind cooling power index and skin and lung stress index", PESD, Vol. 6 no. 1/2012, 2012.

[10] Mihăilă D., Tanasă I. Particularitati climatice ale semestrului rece la Suceava, Analele Univ. „Stefan cel Mare”, Sect. G., T. XV., pag. 61-72, Suceava, 2006.

[11] Mihăilă D., Tanasă I. Particularitati climatice ale semestrului cald la Suceava, Analele Univ. Stefan cel Mare, Sect. G., T. XVI., Suceava, 2007.

[12] Mihăilă D., Tanasă I., Bistricean I. P. Extreme weather interval types in Suceava: frosty and tropical intervals, PESD, Vol. 7, no. 1, 2013.

[13] Mihăilă D., Bistricean P. I., Lazurca L. G. Spatial and temporal relevance of some bioclimatic indices for the study of the bioclimate of Moldova (west of the Prut river), Georeview, Vol 26, No 1, 2016.

[14] Kyle W.J. Summer and winter patterns of human thermal stress in HongKong.Kyle W.J. and Chang C.P. (eds.). Proc. Of the $2^{\text {nd }}$ Int. Conference on East Asia and Western Pacific Meteorology and Climate, Hong Kong. World Scientific, Hong Kong, 557-583, 1992.

[15] Siple P. A., Passel C. F. Measurements of dry atmospheric cooling in subfreezing air temperatures. Proceedings of the American Philosophical Society, 89, 177-199, 1945.

[16] Mihăilă D., Tanasă I. Tendintele evolutiei temperaturii aerului in Podisul Sucevei, Analele Univ. ,Stefan cel Mare”, Sect. G., T. XIV., pag. 57-68, Suceava, 2005.

[17] Besancenot J. P. Premieres donnees sur les stress bioclimatiques moyens en France, Annales de geogr. Nr. 459, LXXXIII, sept. - oct., 1974.

[18] Cheval S., Croitoru A. E., Dragne D., Dragotă C., Gageu O., Patriche C.V., Popa I., Teodoreanu E., Voiculescu M. Indici şi metode cantitative utilizate în climatologie, Edit. Universităţii din Oradea, 2003.

[19] Teodoreanu E., Bunescu I. Thermic comfort, PESD, Nr. 1, Iaşi, 134-142, 2007. 